\title{
Changes in predominant bacterial populations in human faeces with age and with Clostridium difficile infection
}

\author{
M. J. HOPKINS and G. T. MACFARLANE \\ MRC Microbiology and Gut Biology Group, University of Dundee Medical School, Dundee, DD1 9SY
}

\begin{abstract}
The bacterial composition of human faeces can vary greatly with factors such as age and disease, although relatively few studies have monitored these events, particularly at species level. In this investigation, bacteria were isolated from faecal samples from healthy young adults and elderly subjects, and elderly patients with Clostridium difficileassociated diarrhoea (CDAD). The organisms were identified to species level on the basis of their cellular fatty acid profiles with the MIDI system. In some groups of bacteria, species diversity was found to change with age despite the overall numbers of organisms being similar at genus level. Bacteroides thetaiotaomicron, B. ovatus and Prevotella tannerae were common gram-negative anaerobes isolated from young adults. Bacteroides species diversity increased in the faeces of healthy elderly people. Bifidobacterial species diversity decreased with age, with Bifidobacterium adolescentis and Bif. angulatum being the most common isolates. CDAD patients were characterised by greater diversity of facultative species, lactobacilli and clostridia, but greatly reduced numbers of bacteroides, prevotella and bifidobacteria. Such bacterial population changes in the normal microbiota could result in metabolic conditions favourable for the establishment of pathogenic micro-organisms, such as clostridia, and would have considerable effects on the biochemical capacity of the large intestine as a whole. Alterations in the community structure of bifidobacteria and lactobacilli have relevance for dietary and therapeutic interventions such as the use of pre- or probiotics that aim to modify the composition or metabolic activities of the intestinal microflora in a beneficial way, particularly in elderly people or individuals at risk of CDAD.
\end{abstract}

\section{Introduction}

A wide variety of host, microbiological, dietary and environmental factors affects bacterial colonisation of the human large bowel. While metabolic variations in the gut microflora associated with ageing have not been investigated in detail, a limited number of studies has indicated that structural changes occur in the ecosystem in elderly people. Species such as bifidobacteria, which are regarded as being protective, are thought to decline in numbers, whereas clostridia and enterobacterial populations, which are viewed as being detrimental to health, increase $[1,2]$. Previous studies in this laboratory by culture and non-culture-based techniques supported some of these findings [3]. 16S rRNA analysis showed that faecal microbiotas in young adults and the elderly differed significantly from those of

Received 31 Oct. 2001; accepted 16 Dec. 2001.

Correspondence to: Dr M. J. Hopkins (e-mail: m.j.hopkins@ dundee.ac.uk). children up to 8 years of age. Whereas bacterial populations of the elderly and young adults were not considered to differ significantly on the basis of $16 \mathrm{~S}$ rRNA abundances, notable variations were detected in viable counts of bacteria making up these populations at genus level.

In broad terms, the colonic microbiota is generally viewed as being a stable entity within an individual [4], but it is probable that at the level of individual species, considerable variations in bacterial cell populations occur. This was shown in 10 human volunteers who were studied over a 12-month period; it was found that up to 1000-fold differences in counts of Bacteroides spp. (B. fragilis group) occurred during the course of the investigation [5]. Thus, differences at the species level are unlikely to be detected with current genusspecific nucleic acid probes.

Changes in the composition of the intestinal microbiota have been implicated in the initiation or maintenance 
of various disease states [6,7]. A well-known example of this is Clostridium difficile infection causing $C$. difficile-associated diarrhoea (CDAD), which occurs predominantly in patients whose colonic microbiotas have been disturbed by antibiotic therapy [8]. CDAD can be a major problem in elderly hospitalised patients, with the PHLS Communicable Disease Surveillance Centre receiving over $14500 \mathrm{C}$. difficile toxin-positive reports in England and Wales during 2000 (http:// www.phls.co.uk/facts/Gastro/Clostridium/closdifToxAnn. $\mathrm{htm})$. This places a considerable financial and operational burden on the National Health Service. Modification of the large intestinal microbiota by functional foods has been viewed as an attractive method of treatment or prophylaxis for such conditions $[9,10]$. Several non-digestible oligosaccharides are known to stimulate the growth of bifidobacteria, which can in turn affect the growth and metabolism of other microorganisms in the bowel [11-13]. Carbohydrates such as lactulose and fructo-oligosaccharides (FOS) have been shown to affect the growth of $C$. difficile both in vitro and in vivo [14,15]. Detailed information concerning the species composition of the gut flora is essential for understanding the mechanisms involved in such therapies and their suitability for treating different age groups within a population. This paper reports studies in which the predominant culturable bacterial species in the faeces of young adults were compared with those from healthy elderly subjects and patients with CDAD.

\section{Materials and methods}

\section{Subjects}

Fresh faeces samples were collected from three subject groups: healthy young adults, aged 21-34 years $(\mathrm{n}=7)$; healthy elderly people, aged $67-88$ years $(\mathrm{n}=4)$; and elderly patients with CDAD, aged 67-73 years $(n=4)$. Healthy subjects had no history of gastrointestinal complaint or antibiotic therapy within the previous 2 months. CDAD patients had commenced metronidazole treatment and faecal samples were obtained $<24 \mathrm{~h}$ after diagnosis. Faecal samples were collected in sterile plastic universal containers and processed within $1 \mathrm{~h}$ of voiding. Ethical approval and subject consent were obtained for this study.

\section{Bacterial isolation and enumeration}

Faeces were homogenised and serially diluted 10-fold in anaerobic half-strength peptone water. Samples were spread in duplicate on to pre-reduced agar medium and incubated in an anaerobic cabinet $\left(\mathrm{H}_{2} 10 \%, \mathrm{CO}_{2} 10 \%\right.$, $\mathrm{N}_{2} 80 \%$ ) for $48 \mathrm{~h}$ as described previously [16]. The following selective and non-selective agar media were used: Wilkins-Chalgren agar (total anaerobes), WilkinsChalgren agar plus GN selective supplements (Bacteroides, Porphyromonas, Prevotella), cycloserinecefoxitin-fructose agar ( $C$. difficile), Perfringens OPSP agar (C. perfringens), Beerens agar [17] (bifidobacteria), Rogosa agar (lactobacilli) and blood azide agar (enterococci); MacConkey agar no. 2 (enterobacteria) and nutrient agar (facultative species) were incubated for $48 \mathrm{~h}$ at $37^{\circ} \mathrm{C}$ in air. Multiple samples of the predominant colony types were taken from the various media during the counting process for bacterial identification.

\section{Bacterial identification}

All isolates were identified on the basis of their cellular fatty acid (CFA) profiles obtained with the Anaer1 method [18] of the Microbial Identification System (MIDI, Microbial ID, Newark, DE, USA). Fatty acid methyl esters of strict anaerobes were extracted from bacterial cell mass obtained from c. $30 \mathrm{ml}$ of overnight culture in peptone yeast extract broths, whereas facultative species were cultivated on trypticase soy agar [19]. Methylated fatty acids were identified by gas chromatography as reported previously [3], and bacterial identification was determined by CFA profile comparison with standard libraries, Moore and TSBA for strict and facultative anaerobes respectively (http:// www.midi-inc.com/pages/databases.html).

\section{Chemicals}

Bacteriological culture media and selective antibiotic supplements were obtained from Oxoid (Basingstoke, Hants). Unless otherwise stated, all other chemicals were purchased from Sigma (Poole, Dorset).

\section{Results}

Overall, bacterial species diversity varied markedly between different subject groups in this investigation, with the lowest number of species being detected in CDAD patients (Tables 1-4). However, this reduced species diversity was not reflected at genus level because members of the genera Lactococcus, Fusobacterium and Actinomyces were not detected in the young adults or healthy elderly subject groups, but were isolated from patients with CDAD, in whom overall species diversity was low.

\section{Bifidobacteria and lactobacilli}

Bifidobacteria were frequently isolated from the faeces of young adults, particularly Bifidobacterium angulatum, which was found in six out of seven of these subjects and achieved populations as high as $\log _{10}$ $9.8 \mathrm{cfu} / \mathrm{g}$ wet weight faeces (Table 1). Other prevalent species included Bif. longum, Bif. catenulatum and Bif. adolescentis, although the latter two species generally occurred in lower numbers. Bif. angulatum was also the most common isolate in elderly patients, in whom it had the highest bifidobacterial cell count. Bif. adolescentis was the only isolate of this genus that 
Table 1. Populations of bifidobacteria, lactobacilli and lactococci in the faeces of healthy young adults and elderly subjects and CDAD patients

\begin{tabular}{|c|c|c|c|c|c|c|c|c|c|}
\hline \multirow[b]{2}{*}{ Organism } & \multicolumn{3}{|c|}{ Young adults $(\mathrm{n}=7)$} & \multicolumn{3}{|c|}{ Elderly $(n=4)$} & \multicolumn{3}{|c|}{$\operatorname{CDAD}(\mathrm{n}=4)$} \\
\hline & $\begin{array}{l}\text { Number of } \\
\text { isolates }\end{array}$ & Mean* & Range* & $\begin{array}{l}\text { Number of } \\
\text { isolates }\end{array}$ & Mean* & Range* & $\begin{array}{l}\text { Number of } \\
\text { isolates }\end{array}$ & Mean* & Range* \\
\hline Bifidobacterium adolescentis & 5 & $8.0(0.9)$ & $6.7-8.9$ & 1 & $9.6(0.1)$ & NA & 1 & $7.7(0.0)$ & NA \\
\hline Bif. angulatum & 6 & $8.8(0.5)$ & $8.4-9.8$ & 2 & $8.7(1.6)$ & $7.5-9.8$ & & - & - \\
\hline Bif. bifidum & 1 & $7.9(0.1)$ & NA & & - & - & & - & - \\
\hline Bif. catenulatum & 4 & $7.8(0.9)$ & $7.0-8.8$ & & - & - & & - & - \\
\hline Bif. infantis & 1 & $8.3(0.1)$ & NA & & - & - & & - & - \\
\hline Bif. longum & 3 & $8.9(0.1)$ & $8.7-9.0$ & 1 & $9.2(0.0)$ & NA & & - & - \\
\hline Bif. pseudocatenulatum & 1 & $9.1(0.2)$ & NA & & - & - & & - & - \\
\hline Total & 21 & & & 4 & & & 1 & & \\
\hline Lactobacillus acidophilus & 1 & $7.4(0.0)$ & NA & & - & - & & & \\
\hline L. bifermentans & & - & - & & - & - & 1 & $9.4(0.2)$ & NA \\
\hline L. brevis & & - & - & 1 & $6.1(0.0)$ & NA & & - & - \\
\hline L. buchneri & 1 & $5.4(0.1)$ & NA & & - & - & & - & - \\
\hline L. catenaforme & 1 & $7.7(0.0)$ & NA & & - & - & & - & - \\
\hline L. coryneformis subsp. coryneformis & 1 & $6.4(0.0)$ & NA & & - & - & & - & - \\
\hline L. coryneformis subsp. torquens & 1 & $6.2(0.1)$ & NA & & - & - & & - & - \\
\hline L. delbrueckii subsp. bulgaricus & & - & - & 1 & $3.2(0.0)$ & NA & & - & - \\
\hline L. delbrueckii subsp. lactis & 3 & $4.8(1.5)$ & $3.3-6.3$ & 1 & $7.7(0.1)$ & NA & 3 & $7.1(1.0)$ & $6.1-8.1$ \\
\hline L. paracasei subsp. paracasei & 4 & $5.5(1.7)$ & $3.9-7.5$ & 3 & $5.0(1.5)$ & $3.3-6.0$ & 1 & $6.3(0.2)$ & NA \\
\hline L. paracasei subsp. tolerans & & - & - & & - & - & 1 & $8.9(0.1)$ & NA \\
\hline L. pentosus & & - & - & & - & - & 1 & $5.6(0.0)$ & NA \\
\hline L. plantarum & 1 & $5.9(0.0)$ & NA & & - & - & 1 & $6.4(0.0)$ & NA \\
\hline L. reuteri & & - & - & & - & - & 1 & $9.3(0.0)$ & NA \\
\hline L. rhamnosus & 1 & $5.1(0.1)$ & NA & & - & - & & - & - \\
\hline L. rogosae & & - & - & 1 & $4.3(0.0)$ & NA & & - & - \\
\hline L. salivarius & & - & - & & - & - & 1 & $8.0(0.1)$ & NA \\
\hline L. sharpeae & 1 & $3.8(0.0)$ & NA & & - & - & 1 & $8.9(0.0)$ & NA \\
\hline L. vaginalis & & - & - & 1 & $5.9(0.0)$ & NA & & - & - \\
\hline Lactobacillus species D10 & 1 & $9.2(0.1)$ & NA & & - & - & 1 & $10.1(0.1)$ & NA \\
\hline Total & 16 & & & 8 & & & 12 & & \\
\hline Lactococcus lactis & & - & - & & - & - & 1 & $5.9(0.0)$ & NA \\
\hline
\end{tabular}

NA, not applicable; -, not detected.

${ }^{*}$ Results are expressed as mean $\log _{10} \mathrm{cfu} / \mathrm{g}$ wet weight of faeces (SD).

was detected in any of the CDAD patients. Interindividual variation in Lactobacillus populations was high; individual subject groups yielded 6-11 different species, but only $L$. delbrueckii subsp. lactis or $L$. paracasei subsp. paracasei were found in several subjects within the same group.

\section{Clostridia and eubacteria}

C. innocuиm was the most frequently isolated member of this genus in all three subject groups, although numbers of this species were lower in the healthy young adults (Table 2). C. ramosum was also a common isolate in these individuals but was not detected in the faeces of any healthy elderly subjects. C. difficile was found only in the faeces of CDAD patients. The majority of clostridia were saccharolytic, although asaccharolytic species such as C. malenominatum in healthy young and elderly adults and $C$. sporosphaeroides in CDAD patients were also detected. Of the 13 Eubacterium spp. isolated from all patients, only E. rectale, E. biforme and E. limosum were found in more than one subject, with E. biforme achieving the highest faecal populations $\left(\log _{10} 9.2 \mathrm{cfu} / \mathrm{g}\right.$ wet weight).

\section{Bacteroides and prevotella}

Species from these two genera accounted for the majority of bacteria detected in both healthy young and elderly subjects. Prevotella tannerae was prevalent in the faeces of healthy young adults, as were $B$. thetaiotaomicron and $B$. ovatus. B. distasonis, $B$. fragilis and $B$. vulgatus also occurred in numbers in excess of $\log _{10} 9.5 \mathrm{cfu} / \mathrm{g}$ wet weight of faeces but were isolated from less than half of the faecal samples (Table 3). Elderly subjects had a similar profile with respect to the distribution of the major Bacteroides spp., although species diversity was higher with an average of five different Bacteroides spp. in the faeces of each subject. Only one unspeciated Bacteroides isolate was detected in one CDAD subject.

\section{Facultative species}

Table 4 shows that total counts of facultative bacteria were notably higher in CDAD patients $\left(\log _{10} 9.1 \mathrm{cfu} / \mathrm{g}\right.$ wet weight) than in the other two subject groups $\left(\log _{10}\right.$ $7.7 \mathrm{cfu} / \mathrm{g}$ wet weight). Enterobacteria and enterococci were isolated in similar numbers from the CDAD patients, whereas in healthy young adults enterobacterial populations were $c$. 10 -fold lower than enterococci. 
Table 2. Populations of clostridia and eubacteria in the faeces of healthy young adults and elderly subjects and CDAD patients

\begin{tabular}{|c|c|c|c|c|c|c|c|c|c|}
\hline \multirow[b]{2}{*}{ Organism } & \multicolumn{3}{|c|}{ Young adults $(\mathrm{n}=7)$} & \multicolumn{3}{|c|}{ Elderly $(n=4)$} & \multicolumn{3}{|c|}{$\operatorname{CDAD}(\mathrm{n}=4)$} \\
\hline & $\begin{array}{l}\text { Number of } \\
\text { isolates }\end{array}$ & Mean* & Range* & $\begin{array}{c}\text { Number of } \\
\text { isolates }\end{array}$ & Mean* & Range* & $\begin{array}{l}\text { Number of } \\
\text { isolates }\end{array}$ & Mean* & Range* \\
\hline Clostridium clostridioforme & 1 & $7.2(0.0)$ & NA & 1 & $6.9(0.1)$ & NA & 1 & $6.3(0.0)$ & NA \\
\hline C. difficile & & - & - & & - & - & 4 & $7.6(1.2)$ & $6.1-8.7$ \\
\hline C. innосиит & 3 & $6.1(1.2)$ & $5.3-7.4$ & 3 & $7.1(0.7)$ & $6.4-7.7$ & 3 & $9.0(0.6)$ & $8.6-9.7$ \\
\hline C. malenominatum & 2 & $6.5(1.3)$ & $5.6-7.4$ & 1 & $5.6(0.0)$ & NA & & - & - \\
\hline C. novyi & & - & - & & - & - & 1 & $6.4(0.1)$ & NA \\
\hline C. perfringens & 1 & $7.4(0.1)$ & NA & 1 & $8.3(0.0)$ & NA & 1 & $7.5(0.2)$ & NA \\
\hline C. ramosum & 2 & $6.1(1.3)$ & $5.1-7.0$ & & - & - & 2 & $7.9(1.8)$ & $6.6-9.1$ \\
\hline C. sphenoides & 1 & $6.2(0.2)$ & NA & & - & - & & - & - \\
\hline C. sporosphaeroides & & - & - & & - & - & 1 & $9.1(0.3)$ & NA \\
\hline Clostridium species $\mathrm{P}$ & 1 & $6.3(0.0)$ & $\mathrm{NA}$ & & _- & _- & & - & - \\
\hline Clostridium species SPR & 1 & $7.6(0.0)$ & NA & 1 & $7.6(0.0)$ & NA & & - & - \\
\hline Total & 12 & & & 7 & & & 13 & & \\
\hline Eubacterium aerofaciens & 1 & $8.5(0.0)$ & NA & & - & - & & - & - \\
\hline E. alaclolvticum & & - & - & & _- & _- & 1 & $9.0(0.1)$ & NA \\
\hline E. biforme & 1 & $9.2(0.1)$ & NA & 2 & $7.7(1.3)$ & $6.7-8.6$ & & - & - \\
\hline E. contortum & & - & - & & - & - & 1 & $7.0(0.0)$ & NA \\
\hline E. cylindroides & & - & - & 1 & $6.6(0.0)$ & NA & & - & - \\
\hline E. limosum & & - & - & 1 & $8.5(0.0)$ & NA & 1 & $8.0(0.0)$ & NA \\
\hline E. plauti & 1 & $7.7(0.2)$ & NA & & - & - & 1 & $8.7(0.1)$ & NA \\
\hline E. rectale & 2 & $7.5(1.3)$ & $6.5-8.4$ & 1 & $4.3(0.0)$ & NA & & - & - \\
\hline E. timidum & 1 & $7.3(0.0)$ & NA & & - & - & & - & - \\
\hline Total & 6 & & & 5 & & & 4 & & \\
\hline Actinomyces species D01 & & - & - & & - & - & 1 & $5.8(0.1)$ & NA \\
\hline
\end{tabular}

NA, not applicable; - not detected.

${ }^{*}$ Results are expressed as mean $\log _{10} \mathrm{cfu} / \mathrm{g}$ wet weight of faeces (SD).

Table 3. Populations of prevotella, bacteroides and fusobacteria in the faeces of healthy young adults and elderly subjects and CDAD patients

\begin{tabular}{|c|c|c|c|c|c|c|c|c|c|}
\hline \multirow[b]{2}{*}{ Organism } & \multicolumn{3}{|c|}{ Young adults $(n=7)$} & \multicolumn{3}{|c|}{ Elderly $(n=4)$} & \multicolumn{3}{|c|}{$\operatorname{CDAD}(\mathrm{n}=4)$} \\
\hline & $\begin{array}{c}\text { Number of } \\
\text { isolates }\end{array}$ & Mean $^{*}$ & Range $^{*}$ & $\begin{array}{c}\text { Number of } \\
\text { isolates }\end{array}$ & Mean $^{*}$ & Range $^{*}$ & $\begin{array}{c}\text { Number of } \\
\text { isolates }\end{array}$ & Mean $^{*}$ & Range* $^{*}$ \\
\hline Prevotella loescheii & 1 & $9.1(0.2)$ & NA & 1 & $8.3(0.0)$ & NA & & - & - \\
\hline Pr. ruminicola & 1 & $9.5(0.0)$ & NA & & - & - & & - & - \\
\hline Pr. splanchnicus & & - & - & 1 & $9.0(0.0)$ & NA & & - & - \\
\hline Pr: tannerae & 4 & $9.1(0.5)$ & $8.7-9.8$ & 1 & $8.2(0.0)$ & NA & & - & - \\
\hline Prevotella species D64 & 1 & $8.0(0.2)$ & NA & & - & - & & - & - \\
\hline Prevotella species D88 & 1 & $8.7(0.0)$ & NA & & - & - & & - & - \\
\hline Total & 8 & & & 3 & & & & & \\
\hline Bacteroides caccae & 2 & $9.1(0.2)$ & $8.9-9.2$ & 3 & $8.1(0.4)$ & $7.8-8.6$ & & - & - \\
\hline B. distasonis & 3 & $9.3(0.5)$ & $8.9-9.9$ & 3 & $9.3(0.3)$ & $9.0-9.5$ & & - & - \\
\hline B. fragilis & 3 & $9.3(1.0)$ & $8.3-10.3$ & 3 & $8.7(0.2)$ & $8.5-8.9$ & & - & - \\
\hline B. ovatus & 4 & $9.1(0.5)$ & $8.5-9.6$ & 1 & $8.6(0.1)$ & NA & & - & - \\
\hline B. thetaiotaomicron & 5 & $8.8(1.1)$ & $7.4-10.1$ & 3 & $8.6(0.8)$ & $7.7-9.2$ & & - & - \\
\hline B. uniformis cfa 2 & 2 & $9.1(0.4)$ & $8.8-9.4$ & 1 & $9.3(0.0)$ & NA & & - & - \\
\hline B. vulgatus & 3 & $9.3(0.5)$ & $8.9-9.9$ & 3 & $9.0(0.2)$ & $8.9-9.3$ & & - & - \\
\hline Bacteroides species AR & & - & - & 1 & $9.6(0.0)$ & NA & & - & - \\
\hline Bacteroides species FL & & - & - & 1 & $8.6(0.1)$ & NA & & - & - \\
\hline Bacteroides species FO & 1 & $8.3(0.1)$ & NA & & - & - & & - & - \\
\hline Bacteroides species L & & - & - & & - & - & 1 & $9.1(0.1)$ & NA \\
\hline Total & 24 & & & 20 & & & 1 & & \\
\hline Fusobacterium prausnitzii & & - & - & & - & - & 1 & $9.0(0.0)$ & NA \\
\hline F. russii & & - & - & & - & - & 1 & $8.1(0.2)$ & NA \\
\hline Total & & & & & & & 2 & & \\
\hline
\end{tabular}

NA, not applicable; -, not detected.

${ }^{*}$ Results are expressed as mean $\log _{10} \mathrm{cfu} / \mathrm{g}$ wet weight of faeces (SD).

Species diversity was reduced in healthy elderly subjects with only three different organisms being isolated, although enterobacterial populations accounted for a greater proportion of the total microbiota in these subjects.

\section{Discussion}

Although several studies have investigated bacterial populations in the adult large bowel, in various levels of detail $[1,20-22]$, relatively little information is 
Table 4. Populations of facultative species in the faeces of healthy young adults and elderly subjects and CDAD patients

\begin{tabular}{|c|c|c|c|c|c|c|c|c|c|}
\hline \multirow[b]{2}{*}{ Organism } & \multicolumn{3}{|c|}{ Young adults $(\mathrm{n}=7)$} & \multicolumn{3}{|c|}{ Elderly $(n=4)$} & \multicolumn{3}{|c|}{$\mathrm{CDAD}(\mathrm{n}=4)$} \\
\hline & $\begin{array}{l}\text { Number of } \\
\text { isolates }\end{array}$ & Mean* & Range* & $\begin{array}{l}\text { Number of } \\
\text { isolates }\end{array}$ & Mean* & Range* & $\begin{array}{l}\text { Number of } \\
\text { isolates }\end{array}$ & Mean* & Range* \\
\hline Escherichia coli & 3 & $5.7(2.3)$ & $3.3-7.9$ & 3 & $6.2(1.3)$ & $4.8-7.4$ & 2 & $8.5(0.1)$ & $8.4-8.5$ \\
\hline Klebsiella ascorbata & 1 & $5.5(0.0)$ & NA & 2 & $7.9(0.9)$ & $7.2-8.5$ & & - & - \\
\hline K. pneumoniae & 2 & $5.3(0.6)$ & $4.9-5.7$ & & - & - & & - & - \\
\hline Morganella morganii & 2 & $6.1(1.2)$ & $5.2-6.9$ & & - & - & 1 & $7.3(0.0)$ & NA \\
\hline Proteus mirabilis & & - & - & & - & - & 2 & $8.1(0.6)$ & $7.7-8.5$ \\
\hline P. vulgaris & & - & - & & - & - & 1 & $7.9(0.1)$ & NA \\
\hline Serratia fonticola & 2 & $5.7(0.2)$ & $5.5-5.8$ & & - & - & & - & - \\
\hline Total & 10 & & & 5 & & & 6 & & \\
\hline Enterococcus faecalis & 4 & $6.4(1.6)$ & $5.0-8.5$ & 3 & $6.8(0.5)$ & $6.3-7.3$ & 3 & $8.4(0.3)$ & $8.2-8.7$ \\
\hline Micrococcus luteus & & - & - & & - & - & 1 & $7.6(0.1)$ & NA \\
\hline Streptococcus mutans & 2 & $7.4(1.2)$ & $6.5-8.2$ & & - & - & & - & - \\
\hline Total & 6 & & & 3 & & & 4 & & \\
\hline
\end{tabular}

NA, not applicable; -, not detected.

${ }^{*}$ Results are expressed as mean $\log _{10} \mathrm{cfu} / \mathrm{g}$ wet weight of faeces (SD).

available concerning the effects of age on these microbiotas. This study investigated differences in faecal bacteria with both advancing age and $C$. difficile infection and provided information on the species composition of the faecal microbiota. Measurements at species level could be of considerable importance, particularly in bacterial groups that contain pathogenic organisms or those with special nutritional and metabolic capabilities, which would be overlooked if the microbiota is studied at genus level. An example of this was found with the bacteroides; total counts for the genus were slightly higher in young adults but greater species diversity was observed in the elderly (5.0 and 3.4 different Bacteroides isolates per subject in healthy elderly and young adults, respectively).

Bacteroides are nutritionally versatile and can utilise a wide variety of carbon sources. These bacteria are thought to be responsible for the majority of polysaccharide digestion that occurs in the large intestine $[23,24]$. Changes at species level of such a nutritionally prominent population could have considerable consequences for the host, as a result of alterations in microbiota metabolic profiles, and for other communities within the ecosystem, such as hydrogen-utilising syntrophs, that rely on a complex cross-feeding network within the intestine [25].

The microbiotas of elderly patients with CDAD were markedly different from those in healthy elderly subjects, and there was only one Bacteroides isolate from this entire group. Bifidobacteria also occurred in low numbers in these patients and this was reflected in the reduced number of anaerobic species isolated per subject relative to facultative species. The ratio of anaerobic:facultative species isolated per subject in CDAD patients was 3.5:1.0 compared with 5.9:1.0 in healthy elderly subjects. It was probably this reduction in competing anaerobes, which would usually overwhelm smaller populations on agar plates, that allowed detection of fusobacteria and actinomyces, rather than these organisms not being present in other subject groups. This highlights one of the limitations of the viable count method and the enumeration of these bacteria would require the use of procedures that circumvent the necessity to culture and identify organisms, such as fluorescent in-situ hybridisation analyses.

When compared with the healthy elderly group, the CDAD patients not only had higher enterobacterial and enterococcal counts but also had a greater diversity of clostridia and lactobacilli. These changes in the gut microflora may have resulted from metronidazole treatment. Ideally, faecal samples from CDAD patients would have been obtained before antibiotic therapy, but even though faeces were always collected on the day of diagnosis, treatment could not be delayed for the purpose of this study. However, differences in bacterial composition could not all be attributed to the effects of metronidazole because CDAD patients were also found to have high prevalence and viable counts of anaerobic organisms such as clostridia and lactobacilli. This high incidence of lactobacilli with an average of three isolates per patient was unexpected, as these organisms have been used as probiotics to treat $C$. difficile infections [26-28]. This study points towards bacteroides and bifidobacteria as having a more prominent role in colonisation resistance against $C$. difficile, because these organisms were not detected in significant numbers in CDAD patients. This could also extend to prebiotic studies because bifidobacteria are known to have specific substrate preferences [29], and results from this investigation would indicate that substrates that Bif. adolescentis could utilise might be of benefit, because this was the only species detected in CDAD patients. However, the low overall occurrence of bifidobacteria in CDAD patients suggests that a synergic approach, incorporating both pre- and probiotic, would be more likely to be successful. 
At genus level, the number of bifidobacterial isolates declined in healthy elderly subjects compared with young adults. Bif. angulatum was the most common bifidobacterial isolate in healthy young adults, but species diversity was found to decrease with age, with Bif. bifidum, Bif. catenulatum, Bif. pseudocatenulatum and Bif. infantis not being detected in the faeces of elderly subjects. Previous work with culture techniques has identified Bif. adolescentis as the most common bifidobacterial isolate in adults and centenarians [30], although the phenotypically very similar Bif. angulatum was not listed, and may have been overlooked because of the method of identification. The application of PCR found the Bif. catenulatum group and Bif. longum to be more common than Bif. adolescentis in adults, although again, Bif. angulatum was present in few subjects [31]. This latter study showed that the adult microflora generally harboured a combination of three to four different bifidobacterial species, and the results of the present study are in agreement with this observation (average of three bifidobacterial isolates per young adult subject). Prebiotics have been shown to stimulate the growth of species belonging to this genus in vivo $[13,32]$ which confers the potential to suppress growth of other organisms such as enterobacteria [33], or induce changes in large intestinal biochemistry [34]. Again, the presence of bifidobacteria in the colon before any dietary intervention is essential for the successful prophylactic use of prebiotics against intestinal infection or bacterial overgrowth.

The genus Clostridium contains numerous pathogenic species. Total numbers of these bacteria increased by $>\log _{10} 1.5$ in CDAD with high numbers of $C$. difficile, $C$. ramosum, $C$. innocuum and $C$. sporosphaeroides. This concurs with the concept that altered component(s) of the anaerobic microbiota allow proliferation of $C$. difficile, and changes at species, or indeed strain level, could be a reason why CDAD does not ensue in all individuals exposed to antibiotics and environmental challenges [35].

C. malenominatum does not utilise conventional carbohydrate substrates but ferments threonine to propionate and, like C. sporosphaeroides, is able to utilise pyruvate and lactate $[19,36]$. The narrow nutritional requirements of these metabolic specialists suggests their involvement in biochemical interactions between different groups of bacteria in the gut. The large population of $C$. sporosphaeroides in one of the CDAD patients may have been related to increased lactobacilli numbers and lactate production.

Like clostridia, eubacteria have complex nutritional requirements and some members of these genera are relatively close in phylogenetic terms. Eubacteria have been reported to be the second most numerous bacterial group in the large intestine after the bacteroides [20], although results from this study do not confirm this. Such discrepancies are possibly due to the fastidious nature of some members of this genus and differences in identification protocols. Molecular analyses based upon 16S rRNA sequences are confused by the genetic similarity of eubacteria to some clostridia. A probe for the $C$. coccoides group targets some eubacteria and studies have shown that the amount of RNA of this phylogenetic group did not account for more than 16\% of the total bacterial RNA isolated from human faeces compared with $37 \%$ for bacteroides [37]. More recent data from whole-cell hybridisations showed slightly lower mean eubacterial counts than described by Finegold et al. [38], although these cannot be compared directly to the results of the present study, because they expressed them per gram dry weight of faeces [39]. The genus Eubacterium comprises a nutritionally diverse group of organisms that have been implicated in steroid and bile transformation, creating potentially toxic metabolites in the gut, and yet the genus remains poorly characterised and their role in the gut ecosystem is unclear.

In summary, the altered composition of metabolically active groups in the large bowel, such as bacteroides and eubacteria, could lead to profound changes in the biochemical capacity of the gut microbiota with age, and such alterations would not be obvious from studies that are usually made at genus level. In particular, this altered species diversity could have important implications for prebiotic therapy where the choice of carbohydrate would need to target a bifidobacterial species that is likely to be present in members of the subject group. The reduced number of bifidobacterial isolates from elderly subjects suggests that a combination of pre- and probiotic (synbiotic) therapy may be more likely to succeed as a treatment for $C$. difficile infection in the elderly. Furthermore, it is important to realise the limitations of such culture-based studies because large bacterial communities can obscure less dominant populations if suitable selective culture media are not available. Molecular analyses are useful alternatives and can provide ecological information on extremely fastidious organisms, but are themselves limited by oligonucleotide probe design and cellular access. Thus, information from as many sources as possible should be considered when studying bacterial community structure in the large intestine.

\section{References}

1. Gorbach SL, Nahas L, Lerner PI, Weinstein L. Studies of intestinal microflora. Effects of diet, age, and periodic sampling on numbers of fecal microorganisms in man. Gastroenterology 1967; 53: 845-855.

2. Mitsuoka T. Recent trends in research on intestinal flora. Bifidobacteria Microflora 1982; 1: 3-24.

3. Hopkins MJ, Sharp R, Macfarlane GT. Age and disease related changes in intestinal bacterial populations assessed by cell culture, 16S rRNA abundance, and community cellular fatty acids. Gut 2001; 48: 198-205

4. Bornside GH. Stability of human fecal flora. Am J Clin Nutr 1978; 31 Suppl: S141-S144.

5. Meijer-Severs GJ, van Santen E. Variations in the anaerobic 
faecal flora of ten healthy human volunteers with special reference to the Bacteroides fragilis group and Clostridium difficile. Zentralbl Bakteriol Mikrobiol Hyg 1986; 261: 43-52.

6. Masseret E, Boudeau J, Colombel JF et al. Genetically related Escherichia coli strains associated with Crohn's Disease. Gut 2001; 48: 320-325.

7. Larson HE, Welch A. In-vitro and in-vivo characterisation of resistance to colonisation with Clostridium difficile. $J$ Med Microbiol 1993; 38: 103-108.

8. Gerding DN, Gebhard RL, Sumner HW, Peterson LR Pathology and diagnosis of Clostridium difficile disease. In: Rolfe R, Finegold SM (eds) Clostridium difficile: its role in intestinal disease. San Diego, Academic Press. 1988: 259-286.

9. Van Loo J, Cummings JH, Delzenne N et al. Functional food properties of non-digestible oligosaccharides; a consensus report from the 'ENDO' Project (DG XIII AIRII-CT941095). Br J Nutr 1999; 81: 121-132.

10. Vanderhoof JA, Young RJ. Use of probiotics in childhood gastrointestinal disorders. J Pediatr Gastroenterol Nutr 1998; 27: $323-332$

11. Rowland IR, Tanaka R. The effects of transgalactosylated oligosaccharides on gut flora metabolism in rats associated with a human faecal microflora. J Appl Bacteriol 1993; 74 $667-674$.

12. Gibson GR, Wang X. Regulatory effects of bifidobacteria on the growth of other colonic bacteria. J Appl Bacteriol 1994; 77: $412-420$.

13. Gibson GR, Beatty ER, Wang X, Cummings JH. Selective stimulation of bifidobacteria in the human colon by oligofructose and inulin. Gastroenterology 1995; 108: 975-982.

14. Gaskins HR, Mackie RI, May T, Garleb KA. Dietary fructooligosaccharide modulates large intestinal inflammatory responses to Clostridium difficile in antibiotic-compromised mice. Microb Ecol Health Dis 1996; 9: 157-166.

15. Ito $\mathrm{Y}$, Moriwaki $\mathrm{H}$, Muto $\mathrm{Y}$, Kato $\mathrm{N}$, Watanabe $\mathrm{K}$, Ueno $\mathrm{K}$. Effect of lactulose on short-chain fatty acids and lactate production and on the growth of faecal flora, with special reference to Clostridium difficile. J Med Microbiol 1997; 46: $80-84$.

16. Macfarlane GT, Hay S, Gibson GR. Influence of mucin on glycosidase, protease and arylamidase activities of human gut bacteria grown in a 3 -stage continuous culture system. $J$ Appl Bacteriol 1989; 66: 407-417.

17. Beerens H. An elective and selective isolation medium for Bifidobacterium spp. Lett Appl Microbiol 1991; 11: 155-157.

18. Microbial ID. Microbial identification system operational manual. Newark, Microbial ID. 1992.

19. Holdeman LV, Cato EP, Moore WEC (eds). Anaerobe laboratory manual, 4th edn. Blacksburg, Virginia Polytechnic Institute and State University Anaerobe Laboratory. 1977.

20. Finegold SM, Sutter VL, Mathisen GE. Normal indigenous intestinal flora. In: Hentges DJ (ed) Human intestinal microflora in health and disease. New York, Academic Press. 1983: 3-31.

21. Benno Y, Mitsuoka T, Kanazawa K. Human faecal flora in health and colon cancer. Acta Chir Scand 1991; Suppl 62: $15-23$.

22. Franks AH, Harmsen HJM, Raangs GC, Jansen GJ, Schut F, Welling GW. Variations of bacterial populations in human feces measured by fluorescent in situ hybridization with groupspecific 16S rRNA-targeted oligonucleotide probes. Appl Environ Microbiol 1998; 64: 3336-3345.
23. Salyers AA. Bacteroides of the human lower intestinal tract. Annu Rev Microbiol 1984; 38: 293-313.

24. Macfarlane GT, Gibson GR. Co-utilization of polymerized carbon sources by Bacteroides ovatus grown in a two-stage continuous culture system. Appl Environ Microbiol 1991; 57: $1-6$.

25. Gibson GR, Cummings JH, Macfarlane GT. Use of a threestage continuous culture system to study the effect of mucin on dissimilatory sulfate reduction and methanogenesis by mixed populations of human gut bacteria. Appl Environ Microbiol 1988; 54: 2750-2755.

26. Biller JA, Katz AJ, Flores AF, Buie TM, Gorbach SL. Treatment of recurrent Clostridium difficle colitis with Lactobacillus GG. J Pediatr Gastroenterol Nutr 1995; 21: 224-226.

27. Gorbach SL, Chang T-W, Goldin B. Successful treatment of relapsing Clostridium difficile colitis with Lactobacillus $G G$. Lancet 1987; 2: 1519 .

28. Siitonen S, Vapaatalo H, Salminen $\mathrm{S}$ et al. Effect of Lactobacillus $G G$ yoghurt in prevention of antibiotic associated diarrhoea. Ann Med 1990; 22: 57-59

29. Hopkins MJ, Cummings $\mathrm{JH}$, Macfarlane GT. Inter-species differences in maximum specific growth rates and cell yields of bifidobacteria cultured on oligosaccharides and other simple carbohydrate sources. J Appl Microbiol 1998; 85: 381-386.

30. Mutai M, Tanaka R. Ecology of Bifidobacterium in the human intestinal flora. Bifidobacteria Microflora 1987; 6: 33-41.

31. Matsuki T, Watanabe K, Tanaka R, Fukuda M, Oyaizu H. Distribution of bifidobacterial species in human intestinal microflora examined with $16 \mathrm{~S}$ rRNA-gene-targeted speciesspecific primers. Appl Environ Microbiol 1999; 65: 45064512.

32. Ito M, Deguchi Y, Miyamori A et al. Effects of administration of galactooligosaccharides on the human faecal microflora, stool weight and abdominal sensation. Microb Ecol Health Dis 1990; 3: 285-292.

33. Sharp R, Fishbain S, Macfarlane GT. Effect of short-chain carbohydrates on human intestinal bifidobacteria and Escherichia coli in vitro. J Med Microbiol 2001; 50: 152-160.

34. McBain AJ, Macfarlane GT. Modulation of genotoxic enzyme activities by non-digestible oligosaccharide metabolism in invitro human gut bacterial ecosystems. J Med Microbiol 2001; 50: $833-842$

35. Wilcox MH. Clostridium difficile - setting the scene. J Antimicrob Chemother 1998; 41 Suppl C: 1-3.

36. Hippe H, Andreesen JR, Gottschalk G. The genus Clostridium - nonmedical. In: Balows A, Truper HG, Dworkin M, Harder W, Schlefier KH (eds) The Prokaryotes: a handbook on the biology of bacteria: ecophysiology, isolation, identification, applications, 2nd edn. New York, Springer-Verlag. 1992 $1800-1866$

37. Sghir A, Gramet G, Suau A, Rochet V, Pochart P, Dore J. Quantification of bacterial groups within human fecal flora by oligonucleotide probe hybridization. Appl Environ Microbiol 2000; 66: 2263-2266

38. Finegold SM, Attebery HR, Sutter VL. Effect of diet on human fecal flora: comparison of Japanese and American diets. Am J Clin Nutr 1974; 27: 1456-1469.

39. Schwiertz A, le Bay G, Blaut M. Quantification of different Eubacterium spp. in human fecal samples with species-specific 16S rRNA-targeted oligonucleotide probes. Appl Environ Microbiol 2000; 66: 375-382. 